\title{
Los espacios de furia. Política y ciudad a través de las luchas urbanas por la vivienda en Santiago de Chile (1990-2016)
}

Spaces of fury. Politics and the city through the urban struggles for housing in Santiago, Chile (1990-2016)

Alex Paulsen Spinoza [I]

Laura Rodríguez Negrete [II]

Rodrigo Hidalgo Dattwyler [III]

\section{Resumen}

El consenso neoliberal chileno promovido desde la dictadura militar hasta la actualidad, instaló la despolitización de los procesos sociales, donde las luchas por la vivienda fueron contraídas por la vivienda en propiedad. La reclamación contra una ciudad postpolítica, marcada por el conformismo de las desigualdades espaciales y el control de las periferias por medio de la vivienda y el subsidio, logran articular el sentido colectivo del movimiento. A través de la experiencia del movimiento de pobladores Ukamau, este trabajo pretende describir los alcances de sus acciones de reivindicación como actitud de furia en la ciudad de Santiago de Chile. A partir de entrevistas a actores sociales clave del movimiento, buscando reconocer su trayectoria como movimiento social y político.

Palabras clave: despolitización; Ukamau; repolitización; neoliberalismo; Chile.

\begin{abstract}
The Chilean neoliberal consensus, which has been promoted since the military dictatorship, has installed the depoliticization of social processes, where the struggles for housing were added to private property. The claim against a post-political city, marked by conformism in relation to spatial inequalities and the control of peripheries through housing and subsidies, manages to articulate the collective sense of the movement. Through the experience of the Ukamau population movement, this work aims to describe the scope of its claiming actions as an attitude of anger in the city of Santiago de Chile. Based on interviews with the movement's key social actors, the article seeks to recognize its trajectory as a social and political movement.
\end{abstract}

Keywords: depoliticization; Ukamau; repoliticization; neoliberalism; Chile. 
Son pasadas las 7.30 de la mañana del 21 de septiembre de 2016 y en la intersección entre las avenidas Grecia y Américo Vespucio estalla otra más de las luchas urbanas en Chile, sin otro motivo que la vivienda. Los Comités de Allegados de Peñalolén dirigen consignas y reclamaciones hacia el Servicio de Vivienda y Urbanización (Serviu), debido al cambio en las condiciones contractuales del proyecto habitacional El Sauzal. Este nuevo complejo de viviendas, concebido a partir de un proceso participativo involucrando a los diferentes actores estatales, sociales y privados, no alcanza a ser suficiente para aplacar el clamor de las clases trabajadoras por la casa propia. Más que una instancia de diálogo colaborativo para el diseño y construcción del entorno, las reuniones que ahora critican, sucumbieron ante el poder de la rentabilidad de los suelos y el cuerpo político que busca figurar con la inauguración de estos nuevos conjuntos.

El Sauzal y sus excepcionales características lo convierten en pionero dentro de los megaproyectos habitacionales patrocinados por el Estado chileno. Con el fin de integrar a familias de clases populares junto a sectores medios y privilegiando el acceso a la red de transporte y servicios urbanos en general, el sector reúne deseables condiciones de sitio dentro de Santiago de Chile; al mismo tiempo que rompe una tendencia que por más de tres décadas ha expoliado a las familias pobres y dependientes del Estado hacia las periferias (Hidalgo, 2005).

Esta inédita ubicación dentro de la ciudad, de alta plusvalía para el mercado inmobiliario y confort para sus eventuales residentes, escenifica las tensiones espaciales relacionales y curvaturas que la lucha imprime en las geografías del conflicto urbano por la vivienda. Bajo la política de vivienda de integración social inaugurada para 2006, este proyecto solo había reservado un $30 \%$ de viviendas sociales sin deuda versus un $70 \%$ de viviendas para sectores medios, cuyos adquirientes debían ser capaces de contraer una hipoteca. No eran más que nichos de renta para la especulación inmobiliaria, en donde los sectores históricamente vulnerados de Peñalolén debían comenzar una competencia entre desposeídos para acceder a ese tercio de propiedades que detonaban una nueva vida.

Este trabajo propone explorar las actuales experiencias de lucha. Las tensiones de la calle, cubiertas mayoritariamente por los noticiarios, se erigen como ejemplos de la persecución por equidad social y espacial, sin considerar los metaespacios refractarios al neoliberalismo urbano. Los espacios de repolitización, por donde se pierde la mirada sobre lo esencial en las ciudades del Sur Global, son narrados por sus actores y documentados en base a imágenes capturadas en el sitio de los acontecimientos, buscando identificar a la furia de las luchas urbanas.

El paisaje de la ciudad neoliberal tiene una arista de lucha. Las contradicciones generadas los agentes urbanos y sus resultados en el espacio, precisan de una descripción sobre sus movimientos en la ciudad de Santiago. De las implicancias que conllevan estas luchas urbanas, asoman la insostenibilidad del desarrollo de la ciudad y las sucesivas reestructuraciones territoriales metropolitanas, entre otras características. Junto a ellas, se consolida un amplio dispositivo de políticas públicas inauguradas durante la última dictadura militar - 1973 a 1990 - que continúan 
despolitizando al cuerpo social, morigerando el déficit de viviendas con subsidios, esquilmando salarios precarios y expoliando a la población para zonas hiperdegradadas, en favor de los sublimes intereses del capital y la utopía neoliberal espacial.

La llegada de la democracia, en 1990, fue recibida con un déficit cercano al millón de viviendas y con el problema de los allegados como un fenómeno producto de la carestía de vivienda que dejaba la dictadura militar, particularmente en los municipios que componen el Gran Santiago (Hidalgo, 2005). Los movimientos de pobladores y todo tipo de luchas urbanas se retiraron al espacio privado para contemplar la producción masiva de viviendas sociales en las periferias. Desde los discursos oficiales se repetía constantemente que ya no había motivo para entrar en conflicto.

Este consenso se instala respecto al valor político y social que trae consigo la producción de viviendas, que se planteaba como un ejemplo de efectividad ejecutiva nivel regional. Es así que para 1996, el presidente Eduardo Frei Ruiz-Tagle se refiere a los logros alcanzados por los gobiernos de la Concertación de Partidos por la Democracia durante sus primeros seis años, ${ }^{1}$ de la siguiente manera

En primer lugar, podemos mostrar con orgullo nuestro avance sistemático en términos de reducción del déficit habitacional crónico de nuestro país. Hoy en día Chile ocupa el primer lugar en América Latina en construcción de viviendas. En 1995 sobrepasamos la meta fijada para el año, que era de 108.000 viviendas. En 1996 se iniciará la construcción de 130.000 viviendas, cifra inédita que es el resultado de una acción habitacional compartida entre el Gobierno, el empresariado, y la organización y el ahorro de la gente. (Hidalgo, 2005, p. 436)

Estos dispositivos discursivos van a conformar una realidad que se irá agrietando hacia finales del siglo XX con la aparición de otras consecuencias de las políticas habitacionales relacionados a la calidad, como el problema de los con techo (Rodriguez y Sungranyes, 2005). Por su parte, la bancarización de la vivienda social detonaba otro frente de lucha con los deudores habitacionales. Estas dos realidades eran subsumidas bajo el triunfalismo de la política de vivienda masiva, por lo que las luchas urbanas durante los 1990 no se verán como demandas legítimas, sino como prerrogativas de un grupo de personas que solo "quieren que se les regale todo". Esto se ve reforzado por lo que Castillo y Forray (2014) Ilaman la "Política de prevención de tomas", implementada entre 1990 y 1999. Esta política se constituye mediante un proceso de aumento de los subsidios habitacionales y la intensificación de las alianzas con el mundo privado. De hecho, a inicios de los años 2000, los subsidios se utilizarán como una medida de presión para evitar nuevas tomas de terreno (Castillo y Forray, 2014).

Sin embargo, las luchas urbanas por la vivienda tomarán un nuevo impulso hacia 2003, comenzando un ciclo que continuará hasta la actualidad. Ese mismo año se producen tomas en la comuna de Huechuraba; 2004, nuevas ocupaciones de terreno en la comuna de Peñalolén; 2005, pobladores allegados ocupan viviendas recién construidas en La Florida y Peñalolén; en 2006 nuevamente se producen tomas en Peñalolén, 
las cuales son reprimidas por el gobierno, instaurándose el subsidio Diferenciado a la localización. ${ }^{2}$ Como consecuencia de esto, las organizaciones comunitarias y sociales que agrupan bajo el formato de comités de viviendas, iniciando un proceso de rearticulación y reorganización. Recogiendo la experiencia señalada más arriba, hacia 2006 se forma el Movimiento de Pobladores en Lucha (MPL-Peñalolén) (Movimiento de Pobladores en Lucha, 2011); en el 2010 aparece la Federación Nacional de Pobladores (Fenapo, Santiago) (Fenapo, 2014); el movimiento Ukamau, que se agrupa luego de años de lucha en 2011 (Estación CentralUkamau, 2017). En 2018, como si fuera una confederación de luchas y demandas por la vivienda, estos movimientos se articulan en el Frente de Resistencias Urbanas, cohesionando sus horizontes de lucha y reivindicaciones.

Para enmarcar esta escena, se discuten los alcances de los conceptos de ciudad postpolítica, la política, lo político y la policía, los que podrían articular nuevas lecturas sobre las luchas urbanas por la vivienda, más lejanas a la gentrificación y más cercanas a la realidad expoliada de las clases trabajadoras y populares metropolitanas de esta región del globo (Davidson, 2008). Estas articulaciones teóricas se ensamblan precisamente con un trabajo de campo que pretende rescatar las voces de quienes fueron sucesivamente postergados e ignorados por las políticas de vivienda. Se podrá reconocer su voz, pero también identificar las formas en que se encuentran repolitizando el espacio urbano de un Santiago de Chile de furia.
La posdemocracia y la postpolítica en la crisis de la ciudad neoliberal

El prefijo "pos" que caracteriza los conceptos que titulan este sección, tiene su correlato en las palabras de Fukuyama quien, al momento de caer los socialismos reales, celebraba la constitución de una única alternativa: la democracia liberal. Esta nueva etapa releva los fracasos políticos, económicos y sociales de la antigua Unión Soviética y China, plantea el autor, pero, sobre todo, enfatiza en la inviabilidad de un sistema político diferente al neoliberal

[...] las dos guerras mundiales de este siglo y sus concomitantes revoluciones y levantamientos simplemente extendieron espacialmente esos principios, de modo que los diversos reductos de la civilización humana fueron elevados al nivel de sus puestos de avanzada, y aquellas sociedades en Europa y Norteamérica en la vanguardia de la civilización se vieron obligadas a aplicar su liberalismo de manera más cabal. (Fukuyama, 1990, pp. 8-9)

Estos son los cambios que articulan la era de los pos. Así, las vanguardias de civilización que instauran su maquinaria ideológica y discursiva por medio de diferentes tecnologías, se entrecruzan con el sistema económico neoliberal imperante para reestructurar los ambitos de vida en determinadas poblaciones. Se ponen en marcha los mecanismos de reproducción socio-espacial simbólica, que atenúan las contradicciones del sistema 
y las posibles resistencias que se pueden generar, dándole continuidad a un sistema democrático y neoliberal, con capacidad de reproducción socio-espacial libertaria, que debió levantar determinadas utopías para afianzar la hegemonia de los grupos de poder político y económico (Hidalgo et al., 2016). Como señala Crounch, estos síntomas de escenarios posdemocráticos proliferan debido a la preponderancia de grupos empresariales, junto a la conformación y constitución de elites gobernantes que controlan las decisiones importantes de una nación (Crouch, 2004).

Esta posdemocracia es caracterizada por Marquand como el ataque al dominio público por parte del fundamentalismo mercantil económico y la mercantilización del sector público (Marquand, 2004). Las consecuencias espaciales de esta posdemocracia están en la privatización de los espacios públicos, la transformación de las espacialidades de encuentro público, heterogeneidad de las luchas y las estrategias para recapturar el espacio para la emancipación (Purcell, 2008; Barnett, 2004; Low y Smith, 2005; Springer, 2011). Este contexto sociopolítico global se articula con el espacio a través de la ciudad neoliberal y sus dinámicas.

La ciudad neoliberal también se ensambla con una racionalidad tecnocrática y un grupo de actores privados que parecieran consumir y diluír las manifestaciones de lo político. En el primer punto, la racionalidad tecnocrática se refiere a

[...] una administración de cuestiones sociales, económicas u de otro tipo, que permanecen por supuesto complementamente dentro del campo de lo posible, de las relaciones sociales existentes: el máximo indicio de pospolítica en todo los países occidentales, es el crecimiento del enfoque administrativo del gobierno: el gobierno es re-considerado como función administrativa, privado de su dimensión propiamente política. (Swyngedouw, 2014, p. 17)

\section{El orden y la ciudad postpolítica}

Bajo estos postulados, que contradicciones como las anteriormente descritas permanezcan visibles, se debería a que tanto la dinámica de mercado en las ciudades como su elite empresarial terminan por convertirse en habitus y locus para quienes las habitan (Allen, 2004). El statu quo neoliberal cautela esta normalidad, como un bien social en sí y repugna las conductas postpolíticas del disenso, produciendo una política de confortable consenso.

La ciudad postpolítica sería aquella estructura urbana sobre la que operan dispositivos normados para el debate y la tensión, obliterando el malestar y negando lo político. En el espacio del neoliberalismo esto se refleja desde lo normativo, consolidando a la policía y negando lo político, más si son las clases populares quienes enarbolan la lucha (Swyngedouw, 2007). Por otro lado, en el caso de las clases trabajadoras, se construyen escenarios de contención moral y política, presionando la conversión en propiedad desde el lenguaje mismo de producción financiera de espacio consiguiendo esta ciudad postpolítica extinguir la política de los cuerpos por medio del saber experto y trabajadores sociales que reduzcan la 
demanda general de diversos bienes $y$, con ello, generar una única demanda.

De cierta manera, la ciudad es un ejercicio complejo del "reparto de lo sensible", pues el Estado no sólo estaría espacializando el poder, sino que cimentando las condiciones necesarias para la conformación de nichos de renta propicios a la financiarización y mercantilización de las diversas necesidades de los sujetos: salud, vivienda, educación, cultura, ocio, necesidades, entre otros (Rancière, 2009). Siguiendo la propuesta de Rancière, desde aquí se posiciona el concepto de policía, que no cubre solamente el acto de la distribución y jerarquía dentro de un grupo humano, sino que responde a una multiplicidad de procesos reproductores de la contradicción (Rancière, 2006, p. 17). En la espacialidad neoliberal contemporánea, estos procesos son ilustrados desde la desigual distribución de los derechos vinculados a la vivienda, por ejemplo.

Por su parte, la política o emancipación explica los problemas visibles e invisibles en las formas de gobernar y su arte, por medio de los vacíos generados por la policía. La caracterización esencial en la busqueda de igualdad, se representa en cómo los actores o movimientos conforman espacios insurgentes, disidentes, de resistencia, de lucha o de conflicto, hacia la confrontación con las injusticias o desigualdades a la cuales se han visto enfrentados (Oslender, 2007; Swyngedouw, 2017). Como plantea Rancière, la política es una

[...] actividad bien determinada y antagónica a la primera [se refiere a la policía], la que rompe la configuración sensible donde se definen las partes 0 su ausencia por un supuesto que por definición no tiene lugar en ella: la de una parte de los que no tienen parte. (Rancière, 1996, p. 45)

La política se manifiesta en el espacio urbano, entonces, a través de la exigencia de un derecho, y no una retórica de la desigualdad. Quienes no se encuentran insertos o incluidos en el sistema, ya sea por la omisión de la policía en el reparto de lo sensible, pueden hacer uso del espacio a través de su (re)politización, el que aparece:

[...] cuando aquellos que no están incluidos equitativamente en el orden sociopolítico existente, exigen su 'derecho a la igualdad' en nombre de la igualdad, una demanda que llama al ser a lo político, y hace visibles y expone los 'males', las injusticias del orden de policía: este es el lugar y el tiempo de la política, cuando la representación y la articulación de una demanda igualitaria exponen la carencia, lo superfluo, inscritos en el orden de una situación dada. (Swyngedouw, 2011, p. 56)

Las actuales luchas, resistencias, conflictos y movimientos sociales urbanos se situan en un ámbito de la política, puesto que solo a través de ellas se visibilizan las reivindicaciones de los movimientos sociales urbanos, las que no serán concedidas por otra mano distinta al Estado (Di Virgilio, 2015). Las formas de enunciar los desacuerdos y rupturas con el sistema imperante $y$, por lo tanto, construir una voz de quienes no han sido considerados, será denominado lo político. Se podría señalar, entonces, que "lo político será el terreno de encuentro entre la política y la policía en el tratamiento de un daño" (Rancière, 2006, p. 18). El ámbito de "lo 
político" se circunscribe al espacio de disenso que articula la diferencia y negocia el conflicto en un contexto de política consensual de la gobernanza urbana neoliberal, es decir, en la ciudad postpolítica.

\section{En el espesor del espacio urbano chileno: politización, despolitización y repolitización}

Las luchas urbanas por la vivienda son una constante en el espacio-tiempo de Santiago de Chile, sobre todo durante la primera mitad del siglo XX. Hacia 1906 se estatuye la Ley de Habitaciones Obreras, pionera en América Latina. Sus orígenes se remontan a huelgas y reclamaciones contra la miseria urbana reinante en la región, donde la insulabirdad y hacinamiento caracterizan la tensión entre civilización y barbarie (Romero, 1997). La Ilamada cuestión social fue abordada en este marco de acciones, muchas de ellas filantrópicas, particularmente desde la beneficiencia católica y, posteriormente, por la elite gobernante.

La carencia de una política estatal central en los inicios del siglo $X X$, dieron pie para las luchas urbanas de las clases populares y trabajadoras de la época. En la discusión parlamentaria de los primeros años, emergen los primeros indicios sobre la conciencia de un proletario propietario para morigerar el conflicto y sostener el orden social. En una de las sesiones de dichos debates, se señala que

No hay medio más eficaz para desarrollar en el pueblo el espíritu conservador, para hacerlo partidario y defensor del orden y estabilidad sociales, que hacerlo propietario. Se ha probado que no hay trabajador más laborioso, más asiduo y ordenado que el propletario; nunca se le ha visto en desordenes y revueltas. (Espinoza, 1988, p. 36)

A pesar de la consciencia de la clase política en otorgar un status de propietario a las masas populares y trabajadoras, los agentes privados concentraron sus esfuerzos hacia la especulación del suelo urbano generada con el avance en el mejoramiento de la infraestructura y equipamiento de los centros urbanos (Hidalgo, 2005). El encarecimiento de las viviendas y los alquileres fueron excesivos, lo cual motivó la conformación de agrupaciones por la vivienda propia y de arrendatarios que luchaban contra el expolio y el desplazamiento coaccionado por la oligarquía santiaguina (Grez, 2007).

Al mismo tiempo, la política habitacional creaba nuevos planes de vivienda, comprometiendo ambiciosos proyectos en favor del crecimiento urbano con base en viviendas. De esta forma, se atacaba el mal social de las tomas y campamentos, ${ }^{3}$ íconos del asentamiento irregular en latinoamérica. Claro está, que el Estado chileno no podría financiar las treinta mil casas comprometidas, pero sí aportaría al apoyo mutuo y autoconstrucción, llegando sólo al veinte por cien de la oferta señalada en cobertura (Hidalgo, 2005).

Será a mediados de la década de 1960 cuando, desde el esfuerzo y consenso políticos, se crea el Ministerio de Vivienda y Urbanismo que concentrará sus operaciones en la edificación y gestión de los recursos, de la mano con las corporaciones autónomas de vivienda, entorno y servicios. El enfoque que el nuevo gobierno democratacristiano 
persiguió con la Operación Sitio, persistió sobre todo regímen civil o militar, apostando a las llamadas soluciones habitacionales, pero no a la vivienda como hito fijo en el espacio. Con un país-satélite de la Guerra Fría, el defícit habitacional sostuvo las luchas urbanas, las cuales fueron motivadas por la lentitud con la que operó este proyecto.

Con el ascenso de Salvador Allende a la presidencia, el escenario se agudiza en favor de la autogestión y la toma de terrenos, pero sin renunciar a la masiva producción de viviendas. Al imperio de la policía desde arriba, asciende una política desde abajo, materializada por huelga de pagos, paros generales o cortes de vías públicas (Castells, 2014). Es así que durante el último régimen militar del siglo $X X$, se aplicará una intervención en el espacio urbano que desarticulará todo tipo de movimiento de pobladores. Es el inicio del proceso de despolitización de la ciudad. Con la imposición de un nuevo orden político, todos los ámbitos de la vida social fueron severamente disciplinados para la instauración de esta nueva maquinaria, la que por medio de diferentes dispositivos cercenó las posibilidades de una espacialidad democrática.

Esto produjo que la policía llevara a cabo un reparto de lo sensible, limitante sobre las condiciones de igualdad y justicia social para todos. Lo político, como manifestación del disenso, fue desarraigado del espacio junto con la desarticulación del movimiento de pobladores, resultante de la erradicación y expoliación de estos a la periferia de la ciudad y su posterior persecución militar.

El retorno a la democracia para 1990, implicará la contención del disenso por medio de los dispositivos del consenso ¿Cuáles eran las intenciones emergentistas-subyacentes en la constitución de un neoliberalismo espacial que venía consolidando formas de esquilmo y expolio hacia las clases trabajadoras por medio de las supuestas modernizaciones? Evitar los espacios de libertad que se podían generar por medio de lo político, como diría Arendt, o los lugares antagónicos que se producen en toda sociedad que se abre al diálogo o deliberación pública (Mouffe, 2011). La contradicción generada, heredera del nuevo escenario postdictatorial, arroja a un nuevo sujeto urbano, disciplinado "desde arriba" y sometido en las formas de la ciudad postpolítica. El consenso neoliberal, que tempranamente aparece en el léxico de la nueva democracia

Espero de mis compatriotas que nos respetemos mutuamente en nuestras diferencias, que renunciemos a toda suerte de sectarismos o afán hegemónico y que hagamos todo lo posible por entendernos y encontrar caminos de consenso $[\ldots]$ Y a los chilenos que han prosperado contando con la tranquilidad de un orden impuesto por la fuerza, les pido comprender que en las sociedades contemporáneas no hay orden ni seguridad estables sino sobre la base del consenso racional fundado en la justicia. (Gobierno de Chile, 2016)

\section{Voces en los espacios de furia. Entre el derecho y la profundización de la democracia}

En la ciudad postpolítica las voces que repolitizan al espacio urbano provienen de organizaciones sociales altamente coordinadas 
frente a la gobernanza urbana neoliberal. Estos sujetos espinosos para la tecnocraciainstrumental de los planificadores, comienzan a enarbolar discursos que van más allá del acceso a la vivienda y a un barrio digno, para dirigirse a desmantelar los mecanismos de la geografía institucional y profundizar los mecanismos democráticos de un sistema rígido e incuestionado.

Los casos de este tipo no son nuevos. Ya en el acontecer mundial se constatan una serie de levantamientos demandado no solo las necesidades reclamadas, sino que alzando la voz para señalar que la democracia representativa no sería suficiente bajo contextos neoliberales y que se precisa de una democracia radical $y$, en otros casos, de una democracia real ahora, lo que ha sido posible de constatarse a nivel global desde la crisis de 2008, sus ajustes y desgracias (Wilson y Swyngedouw, 2015; Swyngedouw, 2017).

Las formas de lucha que surgen en una ciudad neoliberal son desplegadas por una variedad de medios, los cuales van desde las manifestaciones en las inmediaciones territoriales de los poderes gubernamentales, pasando por huelgas y marchas, hasta repentinas luchas que pretenden impactar en el espacio urbano y en la opinión pública. Las voces que se presentan a continuación fueron extraídas en dos momentos diferentes, pero siempre dentro de la ciudad y su política como un espacio de furia. En primer lugar, en una marcha organizada y en la cual se congregaron varios movimientos que reclaman por vivienda; mientras que, en otro contexto, los testimonios fueron rescatados en el lugar de organización de uno de los movimientos que mayor impacto representa en las luchas urbanas por la vivienda durante estos últimos años, Ukamau.

\section{Espacio de "lo político": la calle}

Retornando al momento ilustrado al inicio del manuscrito, para el 17 de diciembre del 2016, los movimientos por la vivienda se congregaron en una de las arterias más importantes del Gran Santiago, en la inmediatez del resguardado Palacio Presidencial La Moneda. Son las 11 de la mañana, y se presentan más de 300 personas, provenientes desde diferentes sectores de la ciudad, para comenzar a deliberar en público sus discursos de repolitización y democratización del espacio urbano. Dichas peticiones se plasman en folletos que, entregados de mano en mano, hacen alusión a una ley que garantice el derecho a una vivienda, banco de terrenos por comuna, prioridad en la construcción de vivienda sociales y áreas verdes, administración de recursos de construcción de viviendas por parte de las organizaciones sociales, proyectos habitacionales autogestionados y participativos sujetos a las necesidades de los pobladores, fin a los instrumentos de medición de pobreza, condonación a la deuda habitacional de viviendas sociales y la participación vinculante en la elaboración de Planes Reguladores Comunales y Metropolitano.

Una de las formas de tensionar los mecanismos neoliberales, es romper con la tecnocracia imperante en la formulación de proyectos sociales, siendo demandado como una posibilidad de participar en la construcción social de la vivienda. Esto parte de la profundización de la democracia a partir 
Figura 1 - Protesta urbana por la vivienda en Santiago de Chile, zona central próxima al Palacio de La Moneda

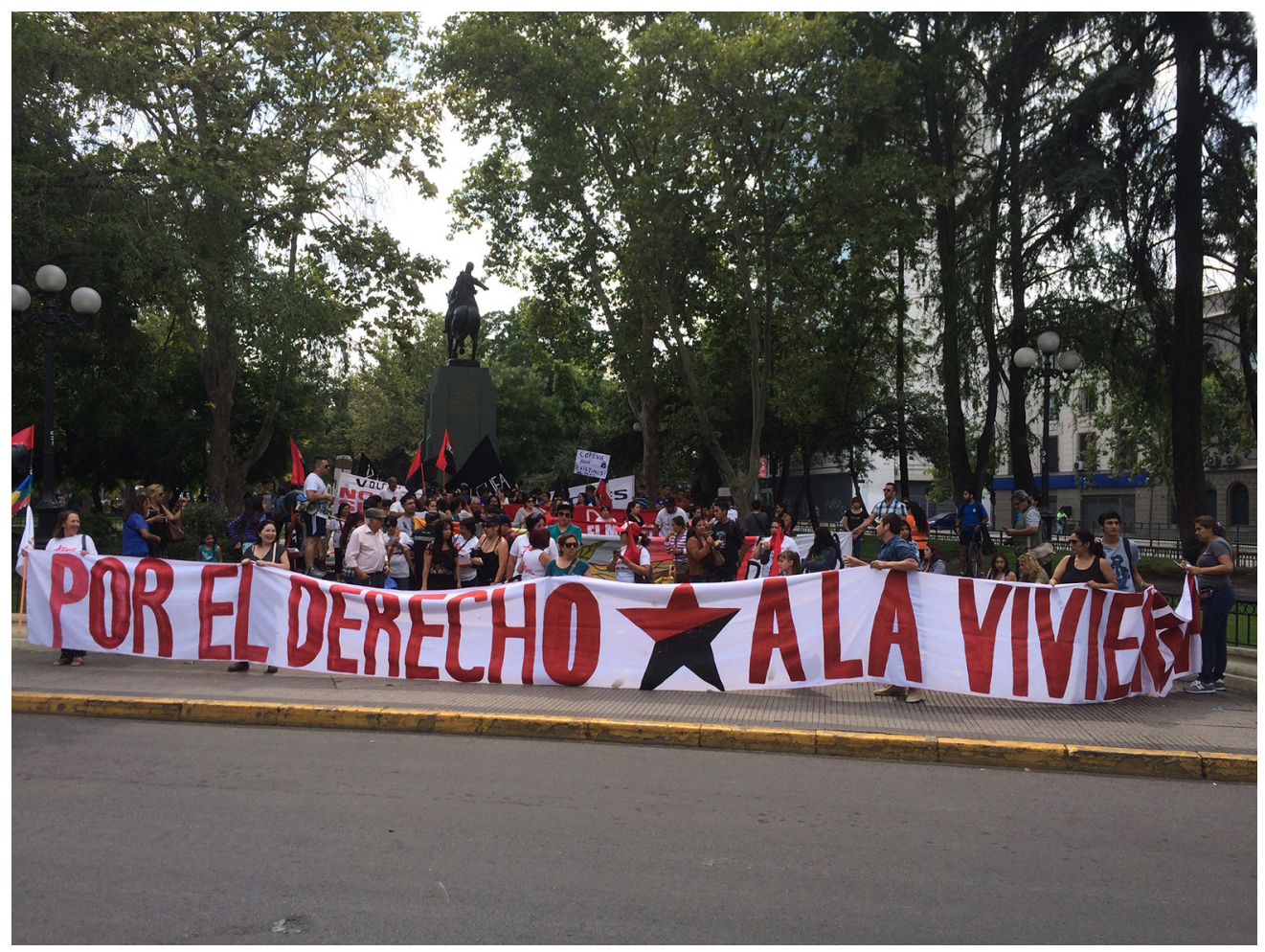

Fuente: Alex Paulsen-Espinoza, 2016.

del espacio, el cual por supuesto, no es neutro (Lefebvre, 1976). Como el espacio es un factor esencial para reconocer los locus enuntiationes, es decir, que la enunciación de los discursos está arraigada/influenciada por el lugar en donde se producen, se rescataron in situ las voces de quienes luchaban en aquel día 17 de diciembre del 2016.

De esta manera, se llevaron a cabo cuatro entrevistas a dirigentes y voceros de los movimientos que actualmente se encuentran luchando por el derecho a la vivienda y a la ciudad. Dos de ellas fueron entrevistas semiestructuradas, mientras que las restantes dos fueron entrevistas en profundidad en los espacios de organización. La primera parte de las entrevistas se realizó en diciembre del 2016, mientras que la segunda en febrero del 2017.

La vocera nacional de la agrupación Ukamau es la primera de ellas. Durante la marcha, se le consulta sobre los orígenes de esta comunidad 
Ukamau nace en 1987 a partir de la lucha de los jóvenes de aquella época que estaban resistiendo la dictadura. Nace como una asociación de talleres culturales, donde principalmente la artesanía movía a la organización. Desde esa fecha hasta hoy, se ha mantenido el tema de la autogestión, de la organización con su comunidad y con su territorio. ${ }^{4}$ En el 2011 emprendemos esta lucha que es la lucha por la vivienda, conformando el movimiento de pobladores Ukamau que viene a dar continuidad proyecto inicial, reclamando que el tema de vivienda no está siendo tocado en la agenda política. Por eso hoy convocamos esta tercera marcha nacional donde se van a hacer actividades a lo largo del país, Arica, Valparaíso, la Región Metropolitana, la Región del Biobío, Magallanes. Ahí estamos coordinando esta fuerza que tiene la organización de pobladores que fue desmembrada y desarticulada durante la dictadura, y que además con este sistema neoliberal, digamos no tiene una coherencia a nivel nacional y eso es lo que estamos bregando hoy en día. (Carmen, vocera nacional movimiento Ukamau, 38 años $)^{5}$

Estas palabras dan muestra de varios aspectos espaciales e históricos de los procesos de despolitización y resistencia, junto a la posterior transición a un consenso neoliberal. En primer lugar, la dictadura aplicó medidas coercitivas severas a los cuerpos de los individuos, lo cual produjo consecuencias sobre las formas en que la sociedad percibía determinados grupos. Esto conllevo a la deshumanización de algunos -sobre todo en aquellos sectores populares- y los transformó en seres superfluos, como diría Arendt (Sánchez, 2015). Frente a esta deshumanización y posterior despolitización, como señala el testimonio, por medio del desmembramiento y desarticulación de las comunidades que enuncian en un espacio "la política", es en donde aparecen comunidades que se resisten. Como organización territorializada y construida espacialmente en sus demandas, Ukamau ejerce estrategias de apropiación espacial por medio de "lo político", es decir, en el establecimiento de espacios de prácticas agonísticas (Mouffe, 2011), de disenso y resistencia al interior de sus barrios en contra de una dictadura violenta, y que por aquellos años desplegaba una de sus olas más represivas, a mediados de la década de 1980.

¿De qué manera se detecta un contexto postpolítico en las democracias actuales? La palabra lucha se constituye en un elemento esencial de los discursos de quienes no han sido considerados en el reparto de lo sensible. A decir de la vocera nacional de Ukamau

Esto fue a partir de un diagnóstico que hicimos en nuestro territorio, que es Estación Central, en la Población Santiago, donde la necesidad más sentida, y donde la gente quería organizarse y luchar era por el tema de la vivienda, por una vivienda digna. $Y$ ahí convocamos a nuestros vecinos, principalmente, y esto rebasó todos los límites y expectativas que teníamos, con unas premisas muy claras, que eran que nos íbamos a organizar y a luchar, y no nos íbamos a poner simplemente en la cola a que cayera la casa del cielo, sino que íbamos a trabajar por eso. Y así es como hemos ido construyendo esta organización, que es una organización que se ha formado al calor de la lucha, es una organización que está conformada principalmente por mujeres y que así también tiene su representación [...] las mujeres somos quienes lideramos esta 
organización y que nos vamos abriendo pasos, vamos abriendo camino, a pesar de muchos cuestionamientos que tenemos por ser mujeres en un sistema capitalista absolutamente patriarcal. (Carmen, vocera nacional movimiento Ukamau, 38 años)

En estas democracias del consenso la palabra lucha constituye un clivaje de estos sistemas republicanos, ya que su legitimidad se ve erosionada al no ser suficientes los mecanismos tecnocráticos vigentes en la construcción de una o unas ideas sobre igualdad y justicia. La práctica espacial accionada por estos grupos hace alusión a modalidades de repolitización, por cuanto son maneras de ir más allá del orden simbólico del contexto posdemocrático (Swyngedouw, 2015). Así como la resistencia es una forma de mantener el statu quo, la lucha pretende modificar el esquema institucional asfixiante de la gubernamentalidad neoliberal.

Durante esta conformación de espacios agonísticos por parte de los grupos convocados para esta marcha como Ukamau, Comité de Vivienda El Volcán II, Comité de Vivienda Vivir Dignamente de La Pintana, Comité de Allegados Esfuerzo Juvenil, Movimiento de Pobladores en Lucha-MPL Peñalolén, Comité de Vivienda "Villa Olímpica", y la Federación

Figura 2 - Protesta urbana del Comité de Vivienda Herradura y Nueva La Habana de La Florida

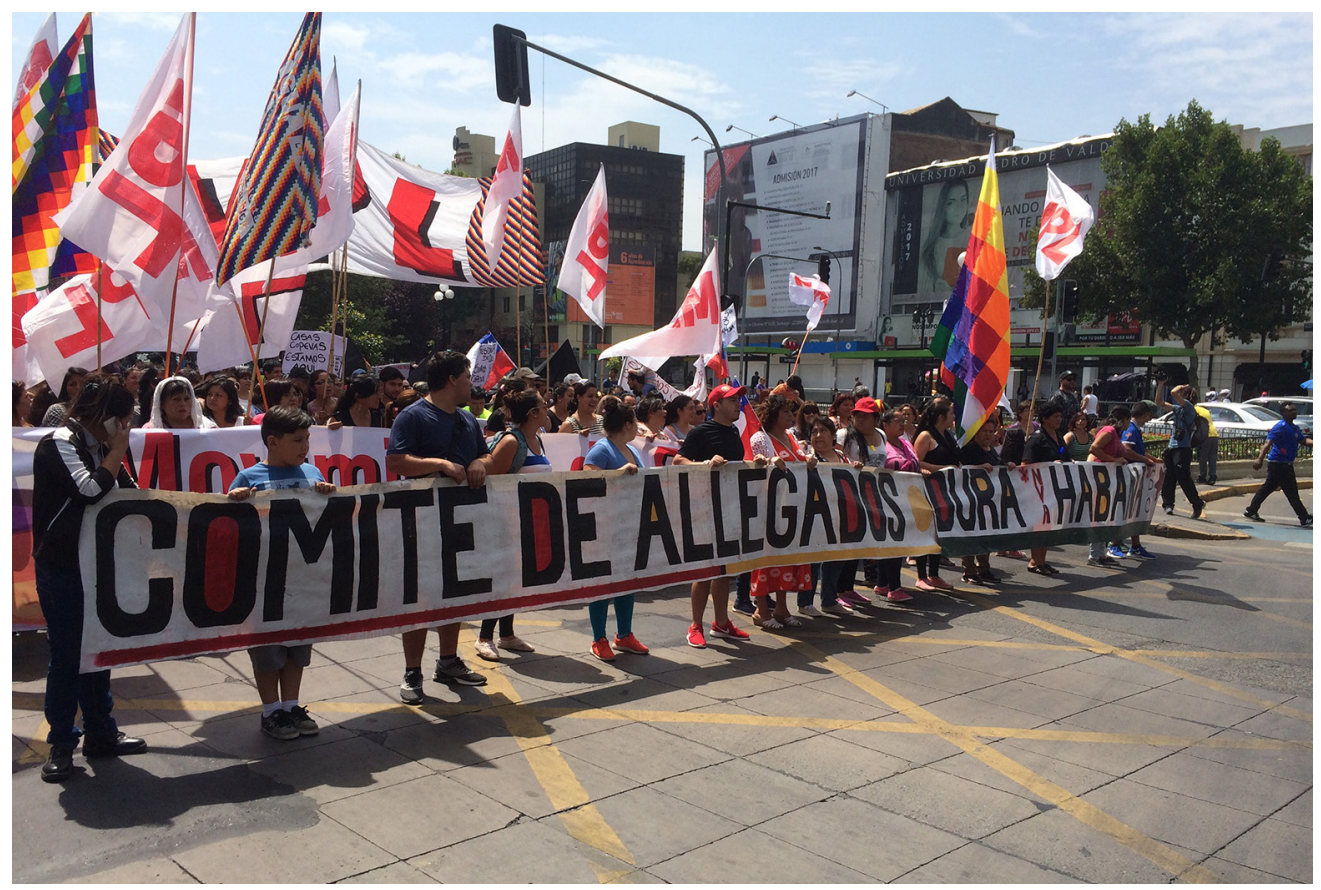

Fuente: Alex Paulsen-Espinoza, 2016. 
Nacional de Pobladores - Fenapo, otros voceros también manifiestan su disenso con las formas de actuar del gobierno central. Un proceso de lucha histórica, según señala el vocero del movimiento Nueva Habana La Florida:

[...] nosotros somos nietos, sobrinos de la generación del campamento Nueva Habana Histórica. Nosotros tenemos un terreno en la mitad de nuestra población y no es justo que construyan ferreterías 0 un edificio que sea pagado, nosotros estamos peleando por ese terreno, tal como peleó la gente de nosotros, nuestros abuelos hace años atrás en el campamento Nueva Habana. Por eso estamos peleando y estamos pidiendo que ahí se construya vivienda para nosotros. (Fabián, vocero movimiento Nueva La Habana, 31 años)

La lucha por la tierra y la vivienda en este sector tiene su origen a inicios de la década de los 1970. Estos terrenos pertenecían al campamento Ranquil, donde vivían hacia esa época cerca de mil quinientas familias, posteriormente ubicadas en los terrenos del antiguo fundo Los Castaños en La Florida durante 1970 (Cofré, 2007). Luego del golpe militar, serán este tipo de poblaciones las que sufrirán los embates de la expoliación por medio de las erradicaciones. De hecho, la comuna de La Florida será uno de los municipios desde donde será expulsada una cantidad considerable de campamentos, con el consecuente desarraigo y la conformación de una homogeneidad social en aquellos sectores en donde llegaban las familias expulsadas. Por su parte, en algunos de los terrenos que quedaban desocupados, se llevaron a cabo proyectos inmobiliarios de envergadura, lo que contribuyó al aumento de los ingresos de las municipalidades y de los agentes privados involucrados (Hidalgo, 2005).

Actualmente, la lucha de estos pobladores se opone a los procesos de especulación y extractivismo inmobiliario que están operando en esos sectores, por cuanto los terrenos en pugna son altamente considerados para el desarrollo de proyectos privados, en virtud de la lógica de la destrucción-creativa y la acumulación por desposesión (Harvey, 2004), sobre todo en comunas emergentes para el sector inmobiliario. Primero fue la dictadura, ahora la gubernamentalidad neoliberal.

\section{Espacio de encuentro y repolitización: la organización}

El segundo momento en la construcción de este relato se adentra en el espacio agonista, en el cual se conforma y constituye el disenso: la casa Ukamau - palabra aymará que significa "así somos"-. Es un día jueves del mes de febrero del 2017 y a eso de las ocho de la noche, comienza a agolparse un grupo de cerca de 60 personas en el pasaje 39 de la Población Santiago. La historia de este sector comienza a gestarse en la década de 1940, cuando un grupo de 90 familias de los cités de Estación Central y la Población Lautaro, deciden tomar los terrenos del Seguro Obrero, en la Ilamada chacra Los Nogales, luego de que la Corporación de Vivienda ${ }^{6}$ (Corvi) no escuchara sus demandas (Ukamau, 2017).

Luego de ello, la generación venidera comenzó a ocupar los terrenos aledaños a esta población en la década de 1960. Con un proyecto gestado desde la Corvi, se instala la Población Santiago. En los años 1980 se 
constituye la casa We Wentru, como un centro de autogestión, reflexión, educación popular, talleres culturales de diversa índole $y$, sobre todo, como un foco de resistencia frente a la dictadura militar. En 1987 cambiará su nombre a casa Ukamau. La lucha por la vivienda comenzará a desarrollarse luego de la constatación de que 425 familias vivían en condición de allegados en el 2010 (Ukamau, 2017).

Una de las fundadoras del movimiento Ukamau, específicamente del comité de vivienda, relata su experiencia en la lucha

Nosotros pertenecíamos a un comité de Creando Chile Mi Barrio, que llegó acá a la Población Santiago, yo era cuidadora de la junta de vecinos que queda a unos pasos más allá [...] Entonces llegaban muchos recursos gubernamentales, y claro, la gente muy acostumbrada a que le lleguen las cosas [...] En un momento se terminó este aporte y dijimos 'ya, se terminaron los recursos ¿qué hacemos?', nos preguntamos con Doris, si la gente no llegaba a las reuniones. Entonces Doris me señalo sobre el déficit de vivienda acá en la comuna de Estación Central y me planteó hacer algo. De hecho, yo tenía un subsidio, ${ }^{7}$ pero quería ayudar a la gente que no tenía vivienda. Comenzamos a convocar gente, y en febrero del 2011 hicimos la primera reunión. En ella sorteamos el nombre del comité de vivienda, y precisamente había dos personas que propusieron el mismo nombre de la casa Ukamau, y se llamó así también el comité [...]. (Viviana, socia organizadora del comité de vivienda Ukamau, 53 años)

El origen de esta lucha hace alusión a una política de vivienda producida a partir de la faceta espacial del neoliberalismo chileno, que en una primera etapa avanzó hacia la masificación de la oferta habitacional, que de todas formas sostuvo una desigual distribución en los subsidios para la adquisición de viviendas. El testimonio anterior señala que existiría un déficit en la comuna de Estación Central, generado por su localización central en el plano metropolitano, lo que ha impactado en la tendencia hacia emplazar las viviendas en sectores periféricos de la ciudad, expoliando a los pobladores de sus arraigos y reivindicaciones con la población.

En virtud de la política de vivienda seguida por los gobiernos concertacionistas, las familias que fueron agrupándose en la casa Ukamau, decidieron vivir en la tierra de sus antepasados y no sufrir el desplazamiento que vivieron cientos de familias al momento de adquirir una vivienda social en la década de 1990. El inicio de esta experiencia es rápidamente atendido por los pobladores del sector:

Empezamos con 12, 15, 20 y después una asamblea completa con más de 100 personas; después dijimos, vamos a tener que formar otro comité, porque en uno ya habían más de 160 y no se podía aceptar más, entonces como Alan tenía la experiencia, ya que había trabajado en algo de vivienda. Tuvimos que formar otro comité, y luego el tercero [...] entonces pensé, que vamos a hacer con tanta gente $[. .$.$] nosotros queríamos un terreno$ chiquitito, para unas 60 o 70 personas, pero luego esto se desbordó [...] luego se empezaron a ver terrenos y ahí dijimos, nosotros queremos quedarnos en Estación Central, siempre quisimos quedarnos acá, no nos íbamos a ir a la periferia, y en ese buscar, salió la maestranza. (Viviana, socia organizadora del comité de vivienda Ukamau, 53 años) 
Si bien la convocatoria a la lucha por la vivienda fue exitosa, para 2010 la casa Ukamau no estuvo exenta de sufrir los dispositivos despolitizadores que aplicaban los gobiernos concertacionistas en la década de 1990. En palabras de la vocera nacional, las medidas disciplinares actuaban de la siguiente forma

Cuando hubo una despolitización y desmembramiento de las organizaciones sociales de aquella época, fue porque el gobierno de la transición [de Patricio Aylwin, 1990-1994] nos dijo que todo iba a cambiar y que venía la alegría. Mucha gente dijo 'en algún momento la alegría llegará, yo ahora me voy a dedicar a trabajar, ya no voy a pelear más por justicia, porque la justicia ya llego, ya no estaban los milicos en la calle', pero en realidad, lo que no todos nos dimos cuenta era que los que se quedaban eran los ladrones de cuello y corbata, que fue la Concertación y hoy Nueva Mayoría; y que seguían con un gobierno de consenso con la derecha, con las fuerzas armadas y que en realidad lo único que había cambiado era que habían sacado a los militares de la calle. (Carmen, vocera nacional movimiento Ukamau, 38 años)

La democracia del consenso no fue cuestionada y los mecanismos de participación siguieron siendo los mismos, además de ser tutelados y protegidos por las castas políticas de la elite gobernante y las fuerzas armadas. La consecuencia de ello han sido las constantes y multitudinarias manifestaciones que comenzaron a resurgir en la primera década del siglo XXI, llegando a un punto álgido hacia 2011, cuando estudiantes y la sociedad civil, apoyaron la necesidad de reformar una política educativa confeccionada en cuatro paredes durante el régimen militar. La conformación de espacios de despolitización durante la década de los noventa, llevo al nacimiento de espectros de políticas radicales frente a los problemas de educación, vivienda y la urgencia de cuestionar y replantear nuestra democracia.

\section{Conclusiones}

Que Chile sea señalado como la cuna del neoliberalismo se debe, probablemente, a la composición de la curvatura descrita. A un escenario de politización masiva, con el gobierno socialista de Salvador Allende, asoma una respuesta despolitizada, homogénea, que aporta a la construcción de una gobernanza neoliberal del consenso, donde a los cuerpos sociales refractarios como Ukamau no les queda otra alternativa que construir base de lucha desde sus propios territorios. Esta trayectoria puede relatarse cronométricamente: politización, 1970 a 1973; despolitización, 1974 a 2003; repolitización, desde 2003 hasta donde sean capaces de consolidarse estas organizaciones, como respuesta al orden de la desigualdad e insustentabilidad.

Porque el proceso de despolitización sí impacta sobre problemas de equidad, detonantes del desacuerdo. Las practicas de la policía, por lo tanto, tienden a dañar la igualdad en todas sus formas de expresión. De esta manera, las decisiones y perjuicios generados por la policía apuntan a actuar sobre la saturación material del espacio social bajo la consigna que la cobertura de oferta en viviendas es, en sí mismo, un artefacto 
de producción para el bienestar social de la población expoliada (Swyngedouw, 2011). Sin embargo, esta carencia es parte de la gobernanza urbana neoliberal y de los sistemas de gobierno en general o lo que algunos denominarian gobernar la precariedad (Lorey, 2016).

El signo de estos relatos es el triunfo de la tecnocracia por sobre lo político y la clausura de aquello que Rancière denomina como sensible. El cuerpo repolitizado de los comités de vivienda, donde Ukamau es sólo uno de varios repartidos a lo largo del país, avizora un nuevo disenso en la trayectoria del modelo neoliberal, donde los mecanismos de respuesta no son necesariamente violentos 0 incendiarios; son, más bien, la manipulación conscientemente política de los instrumentos que el mismo sistema creó para gobernar con eficacia y eficiencia. Los aportes a la vivienda, la lucha por mantenerse en los lugares históricos de las poblaciones o tomas refleja una tradición de resistencia espacial, ahora desde una subversión técnica y comunitariamente resistente. En definitiva

[...] la política no es el ejercicio del poder. La política debe ser definida por sí misma como un modo de actuar específico puesto en acto por un sujeto propio que depende de una racionalidad propia. Es la relación política que permite pensar al sujeto político y no lo contrario. (Rancière, 2006, p. 59)
El consenso instalado en la década de 1990 permitió doblar la oferta residencial generada por el régimen militar y así instalar desde la propiedad, un sistema despolitizado de participación urbana (Hidalgo, 2005). El consumo como circuito metropolitano de agenciamiento neoliberal permitió una aproximación a la paz social y supresión de la contestación social, pero al mismo tiempo expolió a la ciudadanía en el espacio hacia la degradación periférica, sembrando un campo fértil para la repolitización social y la organización de una lucha territorial por la vivienda. Ukamau y otras de estas organizaciones no constituyen una respuesta espontánea a la demanda por vivienda, es un resultado de los procesos de producción de capital, donde aquellos que no tienen la capacidad de pertenecer al consenso, les queda sólo avanzar hacia la lucha.

Seguir la trayectoria de estos puntos de fuga en la ciudad neoliberal es tarea y deber del activismo académico. Más allá de su rol de formación e investigación, debe cumplir con su función de contestar las hegemonías científicas y políticas, que obliteran los espacios estriados del neoliberalismo de Estado. Porque las luchas urbanas por la vivienda seguirán sucediéndose, sin conocer aún límites teóricos. Aunque no se debe olvidar que su objetivo, contradictorio, es la consecución de la propiedad habitacional y pertenecer a la ciudad, más política y justa. 


\section{[I] https://orcid.org/0000-0002-6982-0651}

Pontificia Universidad Católica de Chile, Facultad de Historia, Geografía y Ciencia Política, Instituto de Geografía. Santiago de Chile, Chile.

appaulse@uc.cl

\section{[II] https://orcid.org/0000-0002-0571-9992}

Universidad Austral de Chile, Facultad de Arquitectura y Artes, Instituto de Arquitectura y Urbanismo. Valdívia, Chile.

Irodrigeocultural@gmail.com

\section{[III] https://orcid.org/0000-0001-6092-1547}

Pontificia Universidad Católica de Chile, Facultad de Historia, Geografía y Ciencia Política, Instituto de Geografía. Santiago de Chile, Chile.

rhidalgd@uc.cl

\section{Notas}

(1) La Concertación de Partidos por la Democracia fue conglomerado político que gobernó Chile desde la salida de los militares en 1990 hasta el triunfo de la primera presidencia de Sebastián Piñera en 2010. La Concertación se definió como un eje político de centro-izquierda, que iba desde la Democracia Cristiana hasta el Partido Socialista, pasando por otros partidos de tendencia socialdemócrata.

(2) El subsidio Diferenciado a la localización - Decreto Supremo n. 174 - que se crea en el año 2006 tuvo por objetivo promover la integración social de las viviendas sociales por medio del incentivo a una mejor localización de estas. Este Decreto viene a reaccionar a los problemas socio-espaciales que había generado la Política Habitacional que se había llevado a cabo en la década de 1990, y que consistió en construir viviendas sociales en suelos de un valor más bajo debido a su localización en la periferia.

(3) Las tomas corresponden a acciones colectivas en donde un grupo de personas toman un terreno para llevar a cabo la posterior autoconstrucción de viviendas; luego de este proceso, se formaliza la constitución de un campamento, en donde se produce la instalación de servicios mínimos para la reproducción de la vida.

(4) En adelante la cursiva es nuestra.

(5) Los nombres de los diferentes entrevistados han sido modificados para resguardar su información personal, además de su integridad física y psicológica. Además, agradecemos a los entrevistados su participación en el presente estudio y la posibilidad de acceder a sus experiencias de lucha.

(6) La Corporación de la Vivienda fue una entidad pública que se crea en 1953 a partir de la fusión de la Caja de Habitación Popular y de la Corporación de reconstrucción y Auxilio. Su objetivo estuvo en centralizar la gestión y administración del problema de la vivienda en Chile hasta 1965 cuando se crea el Ministerio de Vivienda y Urbanismo el que va a encargarse de las labores de la vivienda en un solo organismo. 
(7) La entrevistada se refiere a un subsidio de vivienda del Estado que otorga recursos monetarios que cubren un porcentaje del valor de la vivienda, sumándose a ello los ahorros propios. Los programas de subsidios para adquirir una vivienda propia que actualmente se encuentran vigentes son: Subsidio de Integración Social y Territorial (DS.19) para clases medias; Subsidio habitacional DS1 para adquirir viviendas de hasta 90.000 USD; Subsidio habitacional DS1 para adquirir viviendas de hasta 57.000 USD; Subsidio habitacional DS1 para adquirir viviendas de hasta 40.000 USD; Subsidio habitacional DS49 para adquirir viviendas de hasta 38.000 USD.

\section{Referencias}

BARNETT, C. (2004). Deconstructing radical democracy: articulation, representation and being-with-others. Political Geography. Durham, n. 23, pp. 503-528.

CASTELLS, M. (2014). La cuestión urbana. México D.F., Siglo XXI.

CASTILLO, M. y FORRAY, R. (2014). La vivienda, un problema de acceso al suelo. ARQ. Santiago de Chile, n. 86, pp. $48-57$.

COFRÉ, B. (2007). Historia de los pobladores del campamento Nueva La Habana durante la Unidad Popular (1970-1973). Tesis para optar al grado académico de Licenciado. Santiago de Chile, Universidad Arcis.

CROUCH, C. (2004). Posdemocracia. Madrid, Taurus.

DAVIDSON, M. (2008). Spoiled mixture: where does state-led 'positive' gentrification end? Urban Studies, v. 45, n. 12, pp. 2385-2405.

DI VIRGILIO, M. (2015). Urbanizaciones de origen informal en Buenos Aires. Lógicas de producción de suelo urbano y acceso a la vivienda. Estudios Demográficos y Urbanos, v. 30, n. 3.

ESPINOZA, V. (1988). Para una historia de los pobres de la ciudad. Santiago de Chile, Ediciones SUR.

FENAPO (2014). Federación Nacional de Pobladores. Disponible en: https://sites.google.com/site/ elscriptoriumhumanista2014/federacion-nacional-de-pobladores-de-chile-fenapo. Acceso en: 8 marzo 2019.

FUKUYAMA, F. (1990). ¿El fin de la historia? Centro de Estudios Públicos CEP. Santiago de Chile, n. 37, pp. 5-31.

GOBIERNO DE CHILE (2016).El discurso con que Patricio Aylwin reinauguró la democracia. Disponible en: http://www.gob.cl/2014/12/15/el-discurso-con-que-patricio-aylwin-reinauguro-lademocracia/. Acceso en: 8 marzo 2019.

GREZ, S. (2007). Los anarquistas y el movimiento obrero. La alborada de "la Idea" en Chile, 1983-1915. Santiago de Chile, LOM Ediciones.

HARVEY, D. (2004). EI “nuevo” imperialismo: acumulación por desposesión. Socialist Register. Londres, n. 2004, pp. 99-129. 
HIDALGO, R. (2005). La Vivienda Social en Chile y la Construcción del Espacio Urbano en el Santiago del siglo XX. Santiago de Chile, Dibam.

HIDALGO, R., SANTANA, D. y ALVARADO, V. (2016). Mitos, ideologías y utopías neoliberales de la producción del espacio. Hacia una agenda de investigación alternativa. In: HIDALGO, R.; SANTANA, D.; ALVARADO, V.; ARENAS, F.; SALAZAR, A.; VALDEBENITO, C. y ÁlVAREZ, L. (orgs.). En las costas del Neoliberalismo. Naturaleza, Urbanización y Producción Inmobiliaria: experiencias en Chile y Argentina. Santiago de Chile, Serie GEOlibros.

LEFEBVRE, H. (1976). Reflections on the politics of space. Antipode. Londres, v. 8, n. 2, pp. 30-37.

LOREY, I. (2016). Estado de inseguridad. Gobernar la precariedad. Madrid, Traficantes de Sueños.

LOW, S. y SMITH, N. (2005). The politics of public space. Nova York, Routledge.

MARQUAND, D. (2004). Decline of the public. The hollowing out of citizenship. Cambridge, Polity Press.

MOUFFE, C. (2011). En torno a lo político. Buenos Aires, Fondo de Cultura Económica.

MOVIMIENTO DE POBLADORES EN LUCHA (2011). Siete y cuatro. El retorno de los pobladores. Lucha por la vivienda, autogestión habitacional y poder popular en Santiago de Chile. Santiago de Chile, Editorial Quimantú.

OSLENDER, U. (2007). Violence in development: the logic of forced displacement on Colombia's Pacific Coast. Development in Practice, v. 17, n. 6, pp. 752-764.

PURCELL, M. (2008). Recapturing democracy: neoliberalization and the struggle for alternative urban futures. Nova York, Routledge.

RANCIÈRE, J. (1996). El Desacuerdo. Política y filosofía. Buenos Aires, Nueva Visión.

(2006). Política, policía, democracia. Santiago de Chile, Ediciones LOM.

(2009). El reparto de lo sensible: estética y política. Santiago de Chile, LOM Ediciones.

RODRÍGUEZ, A. y SUGRANYES, A. (2005). "El problema de vivienda de los con techo". In: RODRÍGUEZ, A. y SUGRANYES, A. (eds.). Los con techo. Un desafío para la política de vivienda social. Santiago de Chile, Ediciones SUR.

ROMERO, L. (1997). ¿Qué hacer con los pobres? Elite y sectores populares en Santiago de Chile 18401895. Buenos Aires, Editorial Sudamericana.

SÁNCHEZ, C. (2015). Arendt. Estar (políticamente) en el mundo. Valencia, Batiscafo.

SPRINGER, S. (2011). Public space as emancipation: meditations on anarchism, radical democracy, neoliberalism and violence. Antipode. Londres, v. 43, n. 2, pp. 525-562.

SWYNGEDOUW, E. (2007). "The Post-political city". In: BAVO (ed.). Urban politics now. Re-imagening democracy in the neo-liberal city. Rotterdam, NAI-Publishers.

(2011). iLa naturaleza no existe! La sostenibilidad como síntoma de una planificación despolitizada. Urban. Madrid, n. 1, pp. 41-66.

(2014). Where is the political? Insurgent mobilisations and the incipient "return of the political". Space and Polity. Glasgow, v. 18, n. 2, pp. 122-136.

(2017). Ciudadanos insurgentes: el retorno controvertido de lo político en las ciudades postdemocráticas. Revista de Geografía Espacios. Santiago, v. 7, n. 14, pp. 100-113. 
UKAMAU (2017). Ukamau. Disponible en: http://mp-ukamau.blogspot.cl/. Acceso en: 8 marzo 2019.

WILSON, J. y SWYNGEDOUW , E. (2015). "Seeds of dystopia: post-politics and the return of the political". In: WILSON, J. y SWYNGEDOUW, E. (eds.). The Post-Political and its Discontents. Edimburgo, Edinburgh University Press.

Texto recebido em 14/dez/2018

Texto aprovado em 10/jan/2019 